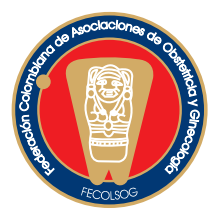

\title{
EDITORIAL
}

\section{¿HACIA DÓNDE VAN \\ LAS GUÍAS EN PRÁCTICA CLÍNICA?}

\section{The next step in guidelines for clinical practice}

Rodrigo Pardo T. , M.D.*

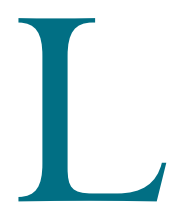

as guías en práctica clínica, una de varias herramientas del sistema de garantía de la calidad en salud, han venido afianzando su importancia en virtud de los beneficios potenciales que brindan a los usuarios de los sistemas de atención y a los proveedores de servicios de salud.

Son poderosos instrumentos que pueden orientar procesos de atención de eventos específicos, contribuir a disminuir la inexplicable variabilidad en las prácticas y facilitar una racionalización de los costos en la provisión de servicios de salud. Sin embargo, no deben olvidarse sus alcances y sus limitaciones.

Aquellas guías que surgían como producto de la experiencia de los especialistas, fueron dando paso a otras formuladas por grupos profesionales o sociedades científicas y finalmente a nuevas versiones construidas desde la participación multidisciplinaria que recogen diferentes saberes y experiencias e introducen perspectivas diversas en un esfuerzo por apropiar la mejor evidencia disponible con el propósito de formular recomendaciones sólidas y aceptadas.

En la actualidad, las guías siguen una rigurosa construcción metodológica y son sometidas a una exigente evaluación por pares a fin de garantizar su validez y confiabilidad.

La elaboración de una guía en práctica clínica es un proceso complejo y costoso que sigue unos pasos secuenciales bien conocidos y aceptados. En

* Profesor Asociado, Instituto de Investigaciones Clínicas, Facultad de Medicina, Universidad Nacional de Colombia. Correo electrónico: rpardot@unal.edu.co una primera etapa, se pretende hacer visible y clara la mejor información disponible en un ejercicio de calificación del nivel de evidencia. En una segunda etapa, se derivan las recomendaciones teniendo en cuenta por una parte, las características del sistema de atención y la factibilidad técnico administrativa y por otra los elementos propios de la cultura que podrían modificar su fuerza o énfasis.

Así, la primera parte es un ejercicio de revisión y construcción de conocimiento, la segunda una aplicación de este conocimiento a un ámbito local, regional o nacional.

Puede decirse que el conocimiento incorporado en las guías es un valor universal y por ello podría ser de utilidad para varios usuarios: la búsqueda de la literatura, la selección de las piezas de información que producen mejores aportes y su apreciación crítica como paso previo a calificar su nivel de evidencia son etapas del proceso que pueden soportar la elaboración de recomendaciones en diferentes países y sistemas de salud, con una economía de recursos y costos. No puede decirse siempre lo mismo de la etapa de la formulación de las recomendaciones, como quiera que ellas incorporan valores locales de la cultura que las convierte en herramienta válida y aceptada. Un requisito para este escenario es que la pregunta que origina la guía sea compartida y de relevancia similar para los posibles diferentes usuarios.

Un mundo con problemas globales exige soluciones similares. La globalización no es un atributo exclusivo de la economía, la política o aún el terrorismo. Lo debe ser igualmente del conocimiento y las guías brindan 
una buena oportunidad para avanzar en un esfuerzo de construcción colectiva, socialmente sensible, universalmente importante y localmente relevante. En esta forma surgen como una atractiva opción de colaboración de grupos involucrados en su desarrollo en diferentes países con distinto grado de desarrollo, de acceso a la información y de expertos metodológicos con capacidad de asesorar a los profesionales y a los usuarios en la discusión de los tópicos particulares de los que se ocupan las guías.

Hay un creciente reconocimiento de la conveniencia de avanzar en este sentido: compartir esfuerzos, experiencias y recursos y lograr resultados en menor tiempo y con costos más razonables. Ello se refiere no solamente a la preparación y revisión de la información disponible, sino también a los procesos de revisión por pares, áreas demostrativas, estudios pilotos y aún elaboración de costos.

Si las guías quieren cumplir cabalmente con su cometido, ellas deben estar disponibles oportunamente, brindar información válida y actualizada y tener un fundamento cuya solidez desborde fronteras geográficas.

De esta manera, a su construcción multidisciplinar que reconoce diversas perspectivas debemos añadir una nueva dimensión: la validez universal de su evidencia.

Allí hay un nuevo reto para la colaboración entre las naciones y las regiones y una oportunidad local para explorar con mayor entusiasmo las particularidades locales de la cultura que convierte un valor universal en una utilidad nacional, regional o local. 